\title{
EXPONENTIAL RANDOM GRAPH MODELS FOR MANAGEMENT RESEARCH: A CASE STUDY OF EXECUTIVE RECRUITMENT
}

\author{
Mary-Paz Arrieta-Paredes* and Bruce Cronin \\ University of Greenwich \\ University of Greenwich Business School, \\ Park Row, Greenwich \\ London SE10 9LS \\ United Kingdom \\ M.ArrietaParedes@greenwich.ac.uk \\ b.cronin@greenwich.ac.uk \\ * Corresponding author
}




\title{
EXPONENTIAL RANDOM GRAPH MODELS FOR MANAGEMENT RESEARCH: A CASE STUDY OF EXECUTIVE RECRUITMENT
}

\begin{abstract}
We introduce a recent development in the statistical analysis of relational data that offers rigorous discrimination of a variety of structural and behavioural effects of interest to management research. Exponential random graph models account for the highly interdependent nature of network data that are problematic for the predominant inferential statistical analysis used in management research. We illustrate the value of the approach with an application focused on executive recruitment by large UK firms, modelling migrations of managers among firms as a network of relationships. We find rigorous statistical support for the influences of industry origin in executive recruitment, particularly in relation to legal and accounting activities. The flexibility and sophisticated relational variables available in the models offer considerable analytical power of value to a wide range of management applications.
\end{abstract}

Keywords: Executive recruitment, industry origin, managerial performance, shareholder value, social network analysis, exponential random graph models

JEL: G32, J24, L25 
Exponential random graph models for management research

\section{RESEARCH HIGHLIGHTS}

- Exponential random graph models (ERGMs) are used as a potentially fruitful analytical method for management research.

- Conventional regression models have limitations in the analysis of highly interdependent data such as network data.

- Case study of an application of ERGMs in explaining drivers of executive recruitment by large UK firms is presented. 


\section{Introduction ${ }^{1}$}

The network paradigm has become increasingly prominent in contemporary management research (Carpenter, Li, \& Jiang, 2012; Kilduff \& Brass, 2010). Organizations and their participants are now frequently conceptualized as socially embedded, with organizational activity seen to have extra-organizational influences and impacts, often via persistent repeated social interactions or networks. However, as the interdependence among and between actors and organizational settings has become more recognized, questions of causality have become more complex. To what extent do people shape networks or are people shaped by them? If there is coevolution of people and networks, how does this unfold (Tasselli, Kilduff, \& Menges, 2015)?

Management research has given little attention to these questions when considering social embeddedness, instead normally simply testing the effect of the presence of network ties via a count of the number of ties (e.g., Li, Popo, \& Zhou, 2008). Alternatively, structural approaches give attention to the characteristics of the network in which the actor or organization is embedded and their position within it, providing opportunities and constraints that may

${ }^{1}$ Abbreviations used in this paper:

ERGM - exponential random graph model.

GoF - goodness of fit.

NACE - statistical classification of economic activities in the European Community

(Nomenclature statistique des activités économiques dans la Communauté européenne). 
determine organizational activity or channel effects of the activity outward, such as the diffusion of innovation. Social network analytic techniques are typically employed to derive a metric indicator of network position for use as an independent variable; many studies, for example, have found actor or organizational performance in various forms associated with the network metric betweenness centrality (e.g., Burt, 1992; Flynn \& Wiltermuth, 2010).

The use of indicators of network position as independent variables in standard inferential statistics is problematic, however, because of the highly interdependent nature of relational data; by definition, such data are not independent nor are the distributions of network ties generally known. Standard inferential statistics, widely used in management research, infers properties of a population from those of a sample on the assumption that both the population and the sample meet a known distribution and each variable has independent effects on the variable of interest. Thus, network data require distinctive analytical treatment both in terms of statistical analysis and in distinguishing structural (network-originating) and selection (actor-originating) effects.

In this paper, we report a recently developed method that appears well positioned to meet the challenges in analyzing relational data in management research. Exponential random graph models (ERGMs) comprise an increasingly popular method in social network analysis to more rigorously model associations among interdependent data than conventional approaches.

ERGMs provide an alternative approach to statistical analysis that can accommodate interdependent data and does not require a priori knowledge or assumptions about sample and population distributions. The models also provide for explicit testing of distinct structural and selection effects. 
Following an introduction and description of ERGMs, we provide a case study applying the method to a problem in managerial research to model determinants of the movements of executives from one company to another. This problem, traditionally addressed as executive recruitment by an autonomous firm, is modelled as a network of movements of executives among firms - recruitment simultaneously filling a vacancy but creating another elsewhere.

\section{The ERGM framework}

A characteristic of the highly interdependent data found in networks is that small changes in connections can have large effects on network structure and the distribution of ties varies greatly from network to network. Outside some attempts to model 'scale-free' distributions approached in very large networks (Barabási, 2000), no a priori assumptions can be made about the distribution of ties in a network. Thus, unlike standard inferential statistics, the characteristics of a network as a whole or the significance of relationships amongst variables cannot be inferred by comparing patterns in the observed data with those in a standard distribution.

In addition, network data, by definition, is highly interdependent and these dependencies are commonly maintained or reinforced by social processes such as reciprocation. It is difficult to isolate individual actor behaviour from the influences of those an actor is connected to. Thus, the observed variables typically lack independence, violating another assumption of standard inferential statistics. Analysis of network data by conventional inferential methods thus tends to generate spurious relationships among variables, resulting in type I errors (Borgatti, Everett, \& Johnson, 2013; Snijders, van de Bunt, \& Steglich, 2010). 
ERGMs employ permutation-based approaches to overcome these limitations of conventional statistical analysis. Rather than assuming independence and a particular distribution of observations, each observed variable is compared with a large number of random permutations of values to determine the extent to which the observation persistently differs from randomness, providing a rigorous measure of statistical significance (Dekker et al, 2007). The approach allows the combination of structural variables (network statistics such as directed ties, mutual ties, transitivity paths and particular microstructures) and actor variables (characteristics of individual actors such as industry, value added or revenue of firm and dyadic selection processes such as reciprocity) into a single model, thus allowing the discrimination of relative structural and selection effects (Robins et al, 2007).

\section{$<$ INSERT FIGURE 1 ABOUT HERE >}

Figure 1 presents some examples of the structural configurations and selection processes that can be included in an ERGM alongside conventional actor variables, such as revenue. The first row provides examples of structural configurations. Inclusion of a) as a variable allows us to test the extent to which the configuration of the observed network is likely to have arisen from distribution of arcs in the network. The count of outward ties, 'outdegree' or 'sources'; inward ties, 'indegree' or 'sinks'; and isolates are important characteristics of a network structure. In a similar manner, we can look for other particular microstructures such as b), c) or d) and test the extent to which each of these is likely to have contributed to the observed network configuration.

The second row of Fig. 1 provides examples of dyadic social selection variables, where network ties arise from the characteristics of the actors. In e) the originator or 'sender' of the relationship possesses an attribute while the 'receiver' does not. With continuous variables, this 
can be interpreted as representing greater amounts of the attribute. In $\mathrm{f}$ ), the receiver possesses an attribute that the sender does not, a social interaction described as 'popularity'. In g), the possessor of an attribute forms a relationship with another possessing the same attribute, 'homophily.' In h), a popular relationship is reciprocated.

The third row of Fig. 1 provides some extensions where attributes are continuous variables, which can nuance the selection effects just described. In i), the absolute difference between the sender and receiver is used as a parameter, indicating heterophily. In $\mathrm{j}$ ), nodes with higher total values in an attribute tend to tie together. In $\mathrm{k}$ ), nodes with a higher product of values tend to tie together. In 1), nodes with a higher attribute tend to both receive ties and send ties. Attribute-based 'instar' and 'outstar' relationships are also readily modelled.

In this manner, quite elaborate configurations of social interaction can be constructed and tested. Elaborations include '4-step cycles', 'social circuits', 'attribute-based centralisation', 'degree assortivity' and cross-level effects. Wang, Robins and Pattison (2009), in their PNet implementation of ERGMs, provide a comprehensive categorization of structural, dyadic and selection variables, with Wang et al (2016) discussing extensions for modelling multilevel networks. Other implementations include the Statnet package for R (Handcock et al, 2003) and the PyMC library for Python (Fonnesbeck et al, 2015).

ERGMs can be more formally considered as allowing the representation of a network as a graph $G$, in terms of summary measures $z(G)$ the network statistics. In mathematical terms (Robins \& Lusher, 2013b), an ERGM assigns probabilities to a given graph $G$ with respect to these statistics, such that the weighted average of the $Z s$ can be stated as 


$$
P_{\boldsymbol{\theta}}(G)=c e^{\theta_{1} z_{1}(G)+\theta_{2} z_{2}(G)+\cdots+\theta_{p} z_{p}(G)}
$$

Expression (1) tells us that the probability of a graph $G$ depends on the number of configurations (network statistics) or some $Z$ functions of them, where $\theta s$ are their parameters and $c$ is a normalized constant (Robins \& Lusher, 2013b). Since the inferential goal is to find data's maximal support under $z(G)$, the estimation of (1) implies solving for the moments equation of $\boldsymbol{\theta}$ via maximum likelihood estimation. Because of natural data dependencies, this is usually done numerically; in our case, it was done by employing a stochastic approximation technique (the Robbins-Monro algorithm) as explained in Koskinen and Snijders (2013), which is solved via convergence to stable values.

It is also important to clarify that the goodness-of fit $(\mathrm{GoF})$ in ERGMs is called a heuristic GoF, which is a simulation of how central or extreme non-fitted effects are in the distribution of the ERGM in equation (1) compared with fitted effects, such that if the graph feature is not extreme, this might have arisen from the estimated model and so it could be explained by the model. The approximate critical value is $\mid t-$ ratio $\mid<2.0$; thus, any value outside this range is considered extreme and hence not a representable graph under the model examined (Koskinen \& Snijders, 2013).

Studies applying ERGMs to management research are relatively recent and scarcely reported. The focus has been on general knowledge transfer, particularly on intra-organizational learning (see for example Skerlavaj, Dimovski \& Desouza, 2010; Su, Huang \& Contractor, 2010) and inter-organizational learning as in Broekel and Hartog (2013), Harris et al (2012) and Lomi and Palotti (2011, 2012). Focardi, Cincotti and Marchesi (2002) apply ERGMs in financial 
markets and Lomi and Fonti (2012) use ERGMs to examine the structural effects of alliances in product markets.

\section{An application of ERGMs to executive recruitment}

The recruitment of an executive manager by a firm not only entails the import of a particular set of individual capabilities but also potentially transfers strategic and organizational knowledge (Brymer, Molloy, \& Gilbert, 2014; Collings, Scullion, \& Morley, 2007; Grimshaw \& Miozzo, 2009; Hansen \& Alewell, 2013; Koch \& McGrath, 1996). In this sense, the value of an external executive appointment is derived from both the characteristics of the individual transferring and the context from which they come (Adner \& Helfat, 2003; Bailey \& Helfat, 2003; Castanias \& Helfat, 2001). Thus, the characteristics of the firm from which an executive originates are a constituent in the subsequent change in value-added capabilities of the recruiting firm. We argue that the complementarity of the origin and recruiting firms and industries is particularly influential in this relationship because decision-making environments can differ greatly, as for example between cement manufacturing and software development.

The recruiting and originating firms, however, do not comprise the full extent of the originating and recruiting context as the movement of an executive from one firm to another in the recruitment process fills a vacancy at the recruiting firm and typically creates one at the originating firm. This vacancy in turn is typically filled by creating a vacancy at another firm; therefore, executive recruitment can be conceived as a network of executive transfers among firms (White, 1970).

Thus, where determinants of executive recruitment have traditionally been analysed with the originating context as independent exogenous variables, ERGMs allow the originating and 
recruiting context to be modelled as endogenous effects of position within a network of transfers. This makes much greater use of the richness of the available data, albeit with a limited exploration in this illustration.

\subsection{Knowledge transfer as a driver of executive recruitment}

Beyond the particular skills and know-how that individual executive managers bring to a recruiting firm, executive migration provides the potential for rich transfer of strategic and organizational knowledge, providing a mechanism for imitation or rapid catch-up with rivals (Aldrich \& Pfeffer, 1976; Almeida \& Kogut, 1999; Dokko \& Gaba, 2012; Kraatz \& Moore, 2002; Rao \& Drazin, 2002). External recruitment is also valuable as a source of additional, complementary or diverse capabilities and as a catalyst for new cognitive models. The capabilities and knowledge imported may be novel, complementary or better match the firm's needs (Adner \& Helfat, 2003; Bailey \& Helfat, 2003; Castanias \& Helfat, 2001; Datta \& Rajagopalan, 1998). External managerial appointments also reconfigure a firm's external relationships to some degree, transferring from the originating firm to the receiving firm a set of interpersonal relationships between the two, with the migrating manager as the intermediary (Broschak, 2004; Pfeffer \& Leblebici, 1973; Rider, 2012). In each of these areas, the experience, knowledge and relationships at the firm of origin in part constitute the capabilities imported.

The potential benefits of external managerial recruitment may be offset by information asymmetry risks compared to proven capabilities of internal candidates, insufficient firmspecific knowledge or organizational disruption in the transition (Ballinger \& Marcel, 2010; Cannella \& Lubatkin, 1993; Greiner, Cummings, \& Bhambri, 2002; Harris \& Helfat, 1997). On 
the contrary, internal appointment may reinforce existing suboptimal practices, limit exposure to different opportunities and have less influence on their peers than very experienced or prestigious outsiders (Finkelstein, 1992; Finkelstein \& Hambrick, 1990; Hambrick, 2007).

This potential benefits from external executive recruitment are realizable though only to the extent that these are made available and are transferable to the recipient organization, that is, particularly where they provide complementary capabilities (Cohen \& Levinthal, 1990; Dokko \& Gaba, 2012; Lane et al, 2006; Zahra \& George, 2002). Where this occurs, executive migration is well positioned to overcome deeply entrenched routines and practices and vested interests that may limit knowledge transfer between organizations through weaker channels. This is particularly true where the migrants transfer from high-prestige or long-tenure settings, conferring status and authority on the migrant (Still \& Strang, 2009). Knowledge transfer is also more likely to be sought in unstable conditions, where institutional or industry norms prove less reliable (Kraatz \& Moore, 2002) or innovations are desired as 'shocks to the system' (Kotabe \& Swan, 1995).

Our argument is that the potential for strategic and organizational knowledge transfer from the originating firm, at least in the long term, is recognized to some extent by recruiting firms. For the reasons outlined above, we think this is most likely where the migrating executive holds complementary capabilities and where they have status to transform existing routines and practices. In both cases, this is more likely when the transfer is from long tenure at a highprestige origin firm but where there is cognitive compatibility between the previous experience and the new one (Still \& Strang, 2009). 
From a resource dependency perspective (Pfeffer \& Salacnick, 1978), in stable conditions, the strategic capabilities sought are likely to be found within the same industry; however, in less stable conditions, experience in strategically important sectors (government, banking, finance) would be valued (Fligstein 1990; Kraatz \& Moore, 2002; Pfeffer \& Leblebici 1973). In an era of increasing attention to shareholder value, we extend the notion of broadly strategically valuable sectors to professional business services more generally, such as accounting and legal services. Partners in large, prestigious auditing and legal services firms will be especially attractive because of their specialist know-how in protecting shareholder interests, particularly in highly regulated or financially dependent firms (Cronin, 2006; Lipartito, 1990, 1998; Nelson et al, 1988).

Executive recruitment, then, is likely to be influenced by particular characteristics of the originating firm and industry complementing the strategic needs of the recruiting firm, and such recruitment should be reflected in increased shareholder value at the recruiting firm. Recruiters will favour executives drawn from complementary industries and firms with high profitability (Campbell, Coff, \& Kryscynski, 2012; Lo et al, 2011; Pazzaglia, Flynn, \& Sonpar, 2012) as a means of importing value-adding capabilities.

H1: In executive recruitment, there is a positive relationship between the source firm's prior financial performance and the likelihood of hiring from that firm.

H2: In executive recruitment, there is a positive relationship between the source firm's industry complementarity and the likelihood of hiring from that firm. 


\subsection{Data and sample selection}

We drew data on executive employment by firm, firm financial indicators and firm industrial classification from Bureau Van Dijk's database Orbis for the 250 largest UK firms by operating revenue in 2006 and the 250 largest in 2011. This spanned a period of unstable conditions in the UK economy, sufficient to capture performance effects on shareholder value (Marshall and Heffes, 2006).

From the firm 'contacts' listings in the Orbis database, we compiled a cohort of 1841 executive managers of the 2006 firms by screening according to conventional executive job titles. We repeated this for the 2011 firms and then matched executives in both datasets who had moved to a distinct firm, that is, where the executive's full name and date of birth were identical in the 2006 and 2011 data and the 2011 firm differed by name from the 2006 firm.

We excluded matches between firms related by ownership, which could represent internal transfer, that is, if the 2011 firm had changed name from the 2006 firm, if the 2011 firm was a subsidiary of the 2006 firm or if both firms had a common global ultimate owner. This left 174 executives in the 2006 group who were serving as executives in distinct firms in the 2011 group, that is, 174 dyadic relationships between a 2006 firm and a 2011 firm, the relationship comprising the migration of an executive from one firm to another. A number of originating and recruiting firms were involved in multiple and chained dyadic relationships, forming a network of inter-firm migrations, as illustrated in Figures 2 and 3. 


\subsection{Model specification}

As presented in equation (1), exponential random graph modelling attempts to maximize the likelihood that a particular set of graphical configurations $\theta$ is associated with the observed network (graph G); that is, it aims to find the maximum likelihood estimation of $\boldsymbol{\theta}$. ERGMs adjust the distribution in equation (1) to diverse network patterns $z(G)$, including both structural and firm-level variables.

As confirmed by some preliminary empirical testing, the sparseness and limited structure evident in the entire network illustrated in Fig. 2 are unlikely to arise from a particular set of structural characteristics; the large number of isolated dyadic relationships could have any number of drivers. Therefore, consistent with the predominant research strategy in social network analysis, we concentrated the analysis on the largest maximally connected subcomponent of 58 firms (Figure 3).

The principal firm-level financial variable as a measure of firm performance and associated driver of executive recruitment is derived from the weighted average cost of capital (WACC). Executive managers actively participate in executive board-level strategic decisions related to firm growth opportunities. WACC is the central focus of discussion of such growth opportunities within a shareholder value perspective.

The specific firm-level variable used in the estimation is residual income, a method of valuing a company calculated following a standard model (Brealey, Myers \& Allen, 2011) from averages for the period 2002-2006 for originating firms and 2007-2011 for recruiting firms:

$$
\boldsymbol{R} \boldsymbol{I}=(R O E-r) I C
$$

where 
RI: Average Residual Income

ROE: Average Return on Equity $=\frac{\text { Earnings Per Share }}{\text { Book equity per share }}$; calculated using profits and losses before taxes

$r$ : Average Cost of Capital (estimated as a WACC, see below)

IC: Average Invested Capital (as per balance sheet, see below)

$$
I C=F A+C A+O C A-(C L+O C L)
$$

where

$I C$ : Average Invested Capital

FA: Average Fixed Assets

CA: Average Current Assets

OCA: Average Other Current Assets

$C L:$ Average Current Liabilities

OCL: Average Other Current Liabilities

We reasonably assume that $0 \leq$ Residual Income, that is, executive managers at least do not destroy shareholder value. Hence, we could rearrange equation (2) such that WACC can approximate $r$, by fitting the following OLS regression separately for originating and recruiting firms:

$$
R O E \times I C=r I C+e_{i}
$$


Thus, $\hat{r}$ is a proxy of the cost of capital $r$ in equation (2) and $e_{i}$ is the error term. Finally, we use the following proxy for the shareholder value of a firm:

$$
S V=\frac{E B I T D A}{\hat{r}}
$$

where EBITDA denotes earnings before interest taxes depreciation and amortization, which we use as an indicator of free cash flows from operations (Pike \& Neale, 2011). The formulation in equation (5) works as an average value of operational cash flows realized in both periods assuming a 'steady state' (Dringoli, 2012). Observe that equation (2) is regarded as the proxy to managerial performance and equation (5) as the proxy to shareholder value. ${ }^{2}$

Firm-level indicators of operational efficiency included operating surplus (operating revenue - total expenses) per employee and cost to operating revenue (total expenses/operating revenue), indicating opportunity costs of additional employees and units of revenue. Industry effects were tested by inclusion of two-digit NACE industrial classification codes for each originating and recruiting firm. We also included a peer group classification and a shareholder independence indicator, drawn from Orbis, to control for differences in corporate governance

${ }^{2}$ Because of the wide range in the managerial performance indicator, residual income, a ranked variable, was also used. This is consistent with a view that recruiters would simply seek to recruit from firms with higher residual income per se rather than specific levels of performance. 
practices. ${ }^{3}$ Finally, we considered the executive's years of tenure in the originating firm, beyond a 3-year minimum, as an indicator of the variable managerial skills, grounded on the axiomatic principle according to which the longer the experience, the better is the managerial decision skills (Henderson et al, 2006).

\subsection{Estimation}

Utilising the PNet implementation of ERGMs (Wang, Robins and Pattison, 2009), we tested a wide range of structural and selection variables as listed in the Appendix and Tables 4 and 5. The discussion is, however, limited to the set of variables that converged to a model of the observed network. These are listed in Table 1.

\section{$<$ INSERT TABLE 1 ABOUT HERE>}

Given that equation (1) denotes a probability model, as it is customary in any logistic regression, conditional odd ratios could be calculated using model estimates to have a more accurate assessment of response probabilities. However, this would make sense only under the assumption that ties compared are in an identical neighbourhood of ties, which might not be the case due to the inherent heterogeneity of relational data. For

${ }^{3}$ The peer group classification subdivides standard industrial classifications by firm size, very large firms within an industry generally characterized by more sophisticated governance mechanisms than smaller firms. The shareholder independence indicator considers the extent to which shareholding is concentrated among a few owners or more dispersed. 
sake of exposition then, we follow the usual practice in ERGM analysis, which is to concentrate on examining agent-level behaviour by contrasting it with structural-level behaviour (see examples in Lusher, Koskinen and Robins, 2013, chps. 12-14). Table 2 presents the results of the ERGM estimation, with the structural effects being essentially descriptive of the arcs from sender to receiver tending to originate or terminate without further structural precedent or consequence.

<INSERT TABLE 2 ABOUT HERE> 


\subsection{Interaction Effects}

In models of dyadic-independence terms alone, it is possible to determine interaction effects. As ERGMs are logit models, coefficients comprise additions to logodds. The probability (logodds) of an edge existing in the network relative to all others is the sum of each change statistics times its coefficients. The change statistic is the amount by which any statistic in the model changes when the edge is added. For example, if we had dummy variables for industry and peer groups, the logodds of an edge between Industry1/PeerGroup1 and Industry1/PeerGroup2, with coefficients $\beta_{1}$ to $\beta_{4}$ for edges, Industry1, Peer Group1 and PeerGroup2, respectively, could be modelled as $\beta_{1}(1)+\beta_{2}(2)+\beta_{3}(1) \times \beta_{4}$ (1).

However, in this application, we are estimating the probability of a network of the observed pattern existing, given the observed characteristics and interactions of its members. Therefore, interaction effects are subsumed within the estimates of more complex dyadicdependent interactions such as in- and out-stars, reciprocity and homophily.

\subsection{Goodness of fit of the ERGMs}

The overall model convergence statistics presented in Table 3 indicate that, in general, this is a very low-density network with a mean degree of 1 , positively skewed both in-degree and out-degree wise, also with low in-degree and out-degree variability. The clustering coefficients for the higher-order patterns reflect the lack of network pattern (up to 0.5). 
Goodness of fit statistics are reported in the Appendix (Tables 4 and 5). Note that 33 out of feasible 42 convergent structures (self-organizing patterns) might have arisen using the model estimated in Table 2. For firm-level attributes, 91 out of a possible total of 110 sub-graphs could have been represented by this model; in particular, 8 out of 10 feasible network patterns could be replicated by Legal and Accounting sender and 11 out of possible 13 by Change in Residual Income Ranking difference. This breakdown between structural- and firm-level attributes makes the model in Table 2 overall a good fit both endogenously and exogenously, but slightly better at the firm-attribute level than at the structural level. Namely, the ERGM estimate explains better exogenous network patterns, particularly when the firm of origin belongs to the Legal and Accounting economic activity of the NACE industrial classification.

Nonetheless, even though Legal and Accounting sender is statistically significant, since Shareholder Value sender and Residual Income sender were not significant, we again did not find evidence in the case under study either in favour or against our research hypothesis, according to which when firms recruit executives from a particular economic activity or industry classification, it is because the underlying strategy is to enhance shareholder value via residual income generation as a way of emulating better performing firms. However, we are in a position to assert that executive managers belonging to 'Legal and Accounting' as the firm of origin prevailed as a network trigger. Namely, the fact of coming from a company that belonged to this industry division was enough to generate a managerial network among executives that changed jobs between '06 and '11. 


\subsection{Discussion of results}

We did not find support for our first hypotheses, and consequently for Fligstein (1990)'s theory of the shareholder value stage, at least from the viewpoint of executive managers' recruitment. Nonetheless, our results support our second hypothesis, adding to the role of industry environment on human capital investment, for we find evidence in the UK case of firmlevel attributes in management recruitment, with predominance in candidate selection from legal and accounting consultancy activity. This outcome is compatible with the works of Kraatz and Moore (2002) in terms of complementary skills and with that of Datta and Rajagopalan (1998) regarding cognitive characteristics compatibility and that of Campbell, Coff, and Kryscynski (2012) because of complementary industry experience in times of increased uncertainty.

Even though we have found evidence of the firm of origin's influence in executive recruitment, in particular legal and accounting activity, this was not concomitant to either shareholder value enhancement or detriment. We have already mentioned executives in the professional services industry accumulate valuable knowledge since their interactions with a wide range of businesses allows them to scan the business environment, in many cases with participation in the development of specific business practices inside leading companies. Therefore, there is potential for a rich transfer of strategic and organizational knowledge in the short or medium term. Furthermore, in this paper we have shown that at least in the case under study, the firm of origin on its own is considered relevant in executive recruitment.

Some of the limitations we faced concern the absence of dynamic parameters, since the study is bounded to one cohort of managers, which not only circumscribes the conceptual framework to the immediately previous employer but also restraints career path analysis. We 
could think of the lack of evidence on the shareholder value transfer as a result of this data absence. As it becomes available, extensions then would involve designing a longitudinal study for the UK, with a wider set of covariates, as well as making international comparisons. This would be particularly useful for considering when firms seek executives from legal and accounting firms, potentially complementing studies noting the recruitment of directors from financial institutions in times of financial distress (Stearns \& Mizruchi, 1993). Additionally, because of the relevance of industry classification aggregate effect, a proper statistical multilevel analysis could be carried out, provided a state-of-the-art network analysis was applied.

\section{Conclusion}

From this illustrative case, it can be seen that ERGMs provide an important set of techniques for the consideration of sophisticated drivers of network structure. Incorporating structural and selection variables alongside traditional parameters, the ERGM approach provides a very flexible method for exploring micro-sociological dynamics that are normally inaccessible to management researchers. The method also overcomes the traditional limitations in undertaking statistical analysis of highly interdependent data that, by definition, characterise networks.

In our case study, the ERGM modelling led us to reject our first hypothesis that firms target external executive hires from firms with relatively higher financial performance, as financial performance in shareholder value or residual income terms were not significantly related to sender or recruiting effects. However, the second hypothesis that firms recruit from industries exercising complementary capabilities was 
supported with regard to legal and accounting origins. No meaningful structural effects were identified, a symptom of the limited cases and hence sparseness of the network. However, the method provides confidence in the findings due to the robustness of the modelling against autocorrelation and multicollinearity problems that arise with conventional regression analysis of highly interdependent data.

Even in their standard implementation, it can be seen that ERGMs provide a versatile platform for management researchers to make much more sophisticated use of the growing availability of network data than conventional methods allow. Emerging multi-level and longitudinal ERGMs offer promising extensions to engage with a wide range of problems in management research. 


\section{REFERENCES}

Adner, R. \& Helfat, C.E. (2003). Corporate effects and dynamic managerial capabilities. Strategic Management Journal, 24(10), 1011-25.

Aldrich, H.E. \& Pfeffer, J. (1976). Environments of organizations. Annual Review of Sociology, 2, 79-105.

Almeida, P., \& Kogut, B. (1999). Localization of knowledge and the mobility of engineers in regional networks. Management Science, 45(7), 905-17.

Bailey, E.E. \& Helfat, C.E. (2003). External management succession, human capital, and firm performance: An integrative analysis. Managerial and Decision Economics, 24(4), 347-69.

Ballinger, G.A. \& Marcel, J.J. (2010). The use of an interim CEO during succession episodes and firm performance. Strategic Management Journal, 31(3), 262-83.

Barabási, A.-L. (2000). Topology of evolving networks: Local events and universality. Physical Review Letters, 85(24), 5234-37.

Borgatti, S.P., Everett, M.G. \& Johnson, J.C. (2013). Analysing social networks. London: Sage. Brealey, R., Myers, S., \& Allen, F. (2011). Principles of corporate finance, $11^{\text {th }}$ edn. New York: McGraw-Hill-Irwin.

Broekel, T. \& Hartog, M. (2013). Explaining the structure of inter-organizational networks using exponential random graph models. Industry and Innovation, 20(3), Special Issue, 277-95. 
Broschak, J.P. (2004). Managers' mobility and market interface: the effect of managers' career mobility on the dissolution of market ties. Administrative Science Quarterly, 49(4), 608-40.

Brymer, R.A., Molloy, J.C., \& Gilbert, B.A. (2014). Human capital pipelines: Competitive implications of repeated inter-organizational hiring. Journal of Management, 40(2), 483-508.

Burt, R.S. (1992). Structural holes: The social structure of competition. Cambridge, MA: Harvard University Press.

Campbell, B.A., Coff, R., \& Kryscynski, D. (2012). Rethinking sustained competitive advantage from human capital. Academy of Management Review, 37(3), 376-95.

Cannella, A. \& Lubatkin, M. (1993). Succession as a sociopolitical process: Internal impediments to outsider selection. Academy of Management Journal, 36(4), 763-93.

Carpenter, M.A., Li, M., \& Jiang, H. (2012). Social network research in organizational contexts: A systematic review of methodological issues and choices. Journal of Management, 38(4), $1328-61$.

Castanias, R.P. \& Helfat, C.E. (2001). The managerial rents model: Theory and empirical analysis. Journal of Management, 27(6), 661-78.

Cohen, M.D. \& Levinthal, D.A. (1990). Absorptive capacity: A new perspective on learning innovation. Administrative Science Quarterly, 35(1), 128-52. 
Collings, D.G., Scullion, H., \& Morley, M.J. (2007). Changing patterns of global staffing in the multinational enterprise: Challenges to the conventional expatriate assignment and emerging alternatives. Journal of World Business, 42(2), 198-213.

Cronin, B. (2006). Networks of advice. International Journal of Knowledge, Culture and Change Management, 5(8), 33-43.

Datta, D.K. \& Rajagopalan, N. (1998). Industry structure and CEO characteristics: An empirical study of succession events. Strategic Management Journal, 19(9), 833-52.

Dekker, D., Krackhardt, D., \& Snijders, T.A.B. (2007). Sensitivity of MRQAP tests to collinearity and autocorrelation conditions. Psychometrika, 72(4), 563-81.

Dokko, G. \& Gaba, V. (2012). Venturing into new territory: career experiences of corporate venture capital managers and practice variation. Academy of Management Journal, 55(3), 56383.

Dringoli, A. (2012). New perspectives on the modern corporation: Corporate strategy and firm growth: creating value for shareholders. Cheltenham, UK: Edward Elgar.

Finkelstein, S. (1992). Power in top management teams: Dimensions, measurement, and validation. Academy of Management Journal, 35(3), 505-38.

Finkelstein, S. \& Hambrick, D.C. (1990). Top-management-team tenure and organizational outcomes: The moderating role of managerial discretion. Administrative Science Quarterly, $35(3), 484-503$. 
Fligstein N. (1990). The transformation of corporate control. Cambridge, Mass.: Harvard University Press.

Flynn, F.J., \& Wiltermuth, S.S. (2010). Who's with me? False consensus bias, social networks, and ethical decision making in organizations. Academy of Management Journal, 53(5), 1074-89.

Focardi, S., Cincotti, S., \& Marchesi, M. (2002). Self-organization and market crashes. Journal of Economic Behaviour and Organization, 49(2), 241-67.

Fonnesbeck, C., Patil, A., Huard, D. \& Salvatier, J. (2015). PyMC 2.3.6 documentation. Retrieved 5.1.16 from http://pymc-devs.github.io/pymc/

Greiner, L., Cummings, T., \& Bhambri, A. (2002). When new CEOs succeed and fail: 4-D theory of strategic transformation, Organizational Dynamics, 32(3), 1-17.

Grimshaw, D. \& Miozzo, M. (2009). New human resource management practices in knowledgeintensive business services firms: The case of outsourcing with staff transfer. Human Relations, 62(10), 1521-50.

Hambrick, D.C. (2007). Upper echelons theory: An update. Academy of Management Review, $32(2), 334-43$.

Handcock, M.S., Hunter, D.R., Butts, C.T., Goodreau, S.M., \& Morris, M. (2003). Statnet: Software tools for the statistical modeling of network data. Retrieved 5.1.16 from http://statnetproject.org 
Hansen, N.K. \& Alewell, D. (2013). Employment systems as governance mechanisms of human capital and capability development. International Journal of Human Resource Management, 24(11), 2131-53.

Harris, D. \& Helfat, C. (1997). Specificity of CEO human capital and compensation. Strategic Management Journal, 18(11), 895-920.

Harris, J. K., Carothers, B. J., Mueller, N. B., Anwuri, V. V., \& James, A. I. (2012). Interpersonal influence among public health leaders in the United States Department of Health and Human Services. Journal of Public Health Research, 1(1), 67-74.

Henderson, A.D., Miller. D. \& Hambrick, D.C. (2006). How quickly do CEOs become obsolete? Industry dynamism, CEO tenure, and company performance. Strategic Management Journal, $27(5), 447-60$.

Kilduff, M. \& Brass, D.J. (2010). Organizational social network research: core ideas and key debates. The Academy of Management Annals, 4(1), 317-57.

Koch, M.J. \& McGrath, R.G. (1996). Improving labor productivity: Human resource management policies do matter. Strategic Management Journal, 17(5), 335-54.

Koskinen, J. \& Snijders, T.A.B. (2013). Simulation, estimation and goodness of fit'. In D. Lusher, J., Koskinen, \& G. Robins (Eds) Exponential random graph models for social networks: Theory, methods and applications, (pp. 141-66). New York: Cambridge University Press; Structural Analysis in the Social Sciences Series. 
Kotabe, M. \& Swan, K. (1995). The role of strategic alliances in high-technology new product development. Strategic Management Journal, 16(8), 621-36.

Kraatz, M. S. \& Moore, J. H. (2002). Executive migration and institutional change. Academy of Management Journal, 45(1), 120-143.

Lane, P.J., Koka, B.R., \& Pathak, S. (2006). The reification of absorptive capacity: A critical review and rejuvenation of the construct. Academy of Management Review, 31(4), 833-63.

Li, J., Poppo, L., \& Zhou, K. (2008). Do managerial ties in China always produce value? Competition, uncertainty, and domestic vs. foreign firms. Strategic Management Journal, 29(4), $383-400$.

Lipartito, K. (1990). What have lawyers done for American business - the case of Baker and Butts of Houston. Business History Review, 64(3), 489-526.

Lipartito, K. (1998). Industrial research and innovation in business. Technology and Culture, 39(4), 777-78.

Lo, T.W., Yang, W.G., Hung, T.S., \& Lai, K.K. (2011). Technological spillovers of transferred inventors from the perspective of social network analysis. African Journal of Business Management, 5 (20), 8192-203.

Lomi, A. \& Fonti, F. (2012). Networks in markets and the propensity of companies to collaborate: An empirical test of three mechanisms. Economics Letters, 114, 216-20. 
Lomi, A. \& Pallotti, F. (2011). Network influence and organizational performance: The effects of tie strength and structural equivalence. European Management Journal, 29(5), Special Issue, $389-403$.

Lomi, A. \& Pallotti, F. (2012). Relational collaboration among spatial multipoint competitors. Social Networks, 34(1), Special Issue, 101-11.

Lusher, D., Koskinen, J., \& Robins, G.L. (Eds.) (2013). Exponential random graph models for social networks: Theory, methods and applications. New York: Cambridge University Press; Structural Analysis in the Social Sciences Series.

Nelson, R.L., Heinz, J.P., Laumann, E.O., \& Salisbury, R.H. (1988). Lawyers and the structure of influence in Washington. Law and Society Review, 22(2), 237-40.

Pazzaglia, F., Flynn, S., \& Sonpar, K. (2012). Performance implications of knowledge and competitive arousal in times of employee mobility: 'the immutable law of the ex'. Human Resource Management, 51(5), 687-707.

Pfeffer, J., \& Leblebici, H. (1973). Executive recruitment and the development of interfirm organisations. Administrative Science Quarterly, 18(4), 449-61.

Pfeffer, J., \& Salancik, G. (1978). The external control of organizations: A resource dependence perspective. New York: Harper and Row.

Pike, R. \& Neale, B., (2011). Corporate finance and investment, $6^{\text {th }}$ edn. London: Pearson. 
Rao, H., \& Drazin, R. (2002). Overcoming resource constraints on product innovation by recruiting talent from rivals: A study of the mutual fund industry, 1986-94. Academy of Management Journal, 45(3), 491-508.

Rider, C.I. (2012). How employees’ prior affiliations constrain organizational network change: A study of U.S. venture capital and private equity. Administrative Science Quarterly, 57(3), 45383.

Robins, G. \& Lusher, D. (2013b). Illustrations: Simulation, estimation and goodness of fit'. In D. Lusher, J. Koskinen, \& G. Robins (Eds.), Exponential random graph models for social networks: Theory, methods and applications (pp. 167-85). New York: Cambridge University Press; Structural Analysis in the Social Sciences Series.

Robins, G., Pattison, P., Kalish, Y., \& Lusher, D. (2007). An introduction to exponential random graph (p*) models for social networks. Social Networks, 29(2), 173-91.

Skerlavaj, M., Dimovski, V., \& Desouza, K.C. (2010). Patterns and structures of intraorganizational learning networks within a knowledge-intensive organization. Journal of Information Technology, 25(2), 189-204.

Snijders, T.A.B., van de Bunt, G.G., \& Steglich, C.E.G. (2010). Introduction to stochastic actorbased models for network dynamics, Social Networks, 32(1), 44-60.

Stearns, L., \& Mizruchi, M. (1993). Board composition and corporate financing: The impact of financial institution representation on borrowing. Academy of Management Journal, 36(3), 60318. 
Still, M.C. \& Strang, D. (2009). Who does an elite organization emulate? Administrative Science Quarterly, 54(1), 58-89.

Su, C.K., Huang, M.K., \& Contractor, N. (2010). Understanding the structures, antecedents and outcomes of organisational learning and knowledge transfer: a multi-theoretical and multilevel network analysis. European Journal of International Management, 4(6), Special Issue, 576-601.

Tasselli, S., Kilduff, M., \& Menges, J.I. (2015). The microfoundations of organizational social networks: A review and an agenda for future research. Journal of Management, 41(5), 1361-87.

Wang, P., Robins, G., \& Pattison, P. (2009). PNet program for the simulation and estimation of exponential random graph $\left(p^{*}\right)$ models, user manual. Melbourne, Australia; Department of Psychology, School of Behavioural Science, University of Melbourne. Retrieved 5.2.16 from http://www.swinburne.edu.au/business-law/research/transformative-innovation/ourresearch/MelNet-social-network-group/PNet-software/resources/PNetManual.pdf Wang, P., Robins, G., Pattison, P., \& Lazega, E. (2016). Social selection models for multilevel networks. Social Networks 44, 346-62.

White, H.C. (1970). Chains of opportunity. Cambridge, MA: Harvard University Press.

Zahra, S.A. \& George, G. (2002). Absorptive capacity: A review, reconceptualization, and extension. Academy of Management Review, 27(2), 185-203. 
Table 1. Convergent variables

\begin{tabular}{|c|c|}
\hline Variable & Description \\
\hline \multicolumn{2}{|l|}{ Structural variables } \\
\hline 2-outstar & $\begin{array}{l}\text { Two executives from the same originating firm move to two } \\
\text { different recruiting firms. }\end{array}$ \\
\hline Arc & Mean executive propensity to move to another firm. \\
\hline Sink & $\begin{array}{l}\text { Number of nodes with zero outdegree; executive leaves } \\
\text { originating firm and no executive joins the originating firm. }\end{array}$ \\
\hline Source & $\begin{array}{l}\text { Number of nodes with zero indegree; executive joins recruiting } \\
\text { firm and no executive leaves the recruiting firm. }\end{array}$ \\
\hline \multicolumn{2}{|l|}{ Firm-level variables } \\
\hline Tenure sender & $\begin{array}{l}\text { Migrating executive's tenure at the originating firm, in years } \\
\text { beyond three. }\end{array}$ \\
\hline Industry homophily & $\begin{array}{l}\text { Originating and recruiting firms have the same industry } \\
\text { classification. }\end{array}$ \\
\hline Legal and Accounting sender & $\begin{array}{l}\text { Originating firm is in legal and accounting industry (NACE 69) } \\
\text { and recruiting firm is not. }\end{array}$ \\
\hline Wholesale and Retail Trade receiver & $\begin{array}{l}\text { Recruiting firm is in wholesale and retail trade industry (NACE } \\
47 \text { ) and originating firm is not. }\end{array}$ \\
\hline Peer Group homophily & $\begin{array}{l}\text { Originating and recruiting firms have the same peer group } \\
\text { classification. }\end{array}$ \\
\hline Shareholder Independence homophily & $\begin{array}{l}\text { Originating and recruiting firms have the same shareholder } \\
\text { independence classification. }\end{array}$ \\
\hline Residual Income sender & $\begin{array}{l}\text { Originating firm's residual income greater than that of } \\
\text { recruiting firm. }\end{array}$ \\
\hline $\begin{array}{l}\text { Change in Residual Income Ranking } \\
\text { sender }\end{array}$ & $\begin{array}{l}\text { Increase in originating firm's residual income rank 2006-11 } \\
\text { greater than that of recruiting firm. }\end{array}$ \\
\hline $\begin{array}{l}\text { Change in Residual Income Ranking } \\
\text { difference }\end{array}$ & $\begin{array}{l}\text { Change in originating firm's residual income rank 2006-11 } \\
\text { differs from change in recruiting firm rank. }\end{array}$ \\
\hline Operating Surplus/Employee sender & $\begin{array}{l}\text { Originating firm's operating surplus per employee greater than } \\
\text { that of recruiting firm. }\end{array}$ \\
\hline Operating Surplus/Employee difference & $\begin{array}{l}\text { Originating firm's operating surplus per employee differs from } \\
\text { that of recruiting firm. }\end{array}$ \\
\hline Cost/Revenue Ratio sender & $\begin{array}{l}\text { Originating firm's operating costs/operating revenue ratio } \\
\text { greater than that of recruiting firm. }\end{array}$ \\
\hline Cost/Revenue Ratio difference & $\begin{array}{l}\text { Originating firm's operating costs/operating revenue ratio } \\
\text { differs from that of recruiting firm. }\end{array}$ \\
\hline Shareholder Value sender & $\begin{array}{l}\text { Originating firm's shareholder value greater than that of the } \\
\text { recruiting firm. }\end{array}$ \\
\hline Shareholder Value receiver & $\begin{array}{l}\text { Recruiting firm's shareholder value greater than that of the } \\
\text { originating firm. }\end{array}$ \\
\hline
\end{tabular}


Exponential random graph models for management research

Shareholder Value difference

Originating firm's shareholder value differs from that of recruiting firm. 
Table 2. ERGM Estimation

\begin{tabular}{|c|c|c|c|c|}
\hline Parameters & Estimate & & $\begin{array}{l}\text { Standard } \\
\text { error (SE) }\end{array}$ & $\begin{array}{l}\text { Convergence } \\
\text { statistic } \\
\end{array}$ \\
\hline \multicolumn{5}{|l|}{ Structural } \\
\hline 2-outstar & -0.19 & & 0.21 & 0.04 \\
\hline Arc & -4.21 & * & 0.71 & 0.04 \\
\hline Sink & 0.79 & $*$ & 0.73 & 0.01 \\
\hline Source & 3.22 & $*$ & 0.74 & 0.02 \\
\hline \multicolumn{5}{|l|}{ Firm-level } \\
\hline Tenure sender & 0.10 & & 0.08 & -0.01 \\
\hline Industry homophily & 0.21 & & 0.65 & -0.07 \\
\hline Legal and Accounting sender & 5.62 & $*$ & 2.11 & 0.05 \\
\hline Wholesale and Retail Trade receiver & -1.95 & & 1.05 & -0.05 \\
\hline Peer Group homophily & 0.36 & & 0.79 & 0.04 \\
\hline Shareholder Independence homophily & -0.28 & & 0.42 & -0.04 \\
\hline Residual Income sender & 0.09 & & 0.10 & 0.06 \\
\hline Change in Residual Income Ranking sender & -0.18 & & 0.13 & 0.05 \\
\hline Change in Residual Income Ranking difference & -0.12 & $*$ & 0.06 & 0.02 \\
\hline Operating Surplus per Employee sender & -0.20 & & 0.14 & -0.01 \\
\hline Operating Surplus per Employee difference & -0.01 & & 0.09 & 0.00 \\
\hline Cost/Revenue Ratio sender & -0.03 & & 0.07 & 0.05 \\
\hline Cost/Revenue Ratio difference & 0.00 & & 0.04 & 0.01 \\
\hline Shareholder Value sender & 0.14 & & 0.11 & 0.02 \\
\hline Shareholder Value receiver & 0.03 & & 0.07 & 0.03 \\
\hline Shareholder Value difference & -0.13 & & 0.07 & 0.05 \\
\hline
\end{tabular}

* Significant at approximately $p<0.05$ level 
Table 3. Convergence statistics

Global Clustering Coefficients

\begin{tabular}{ll}
\hline Cto & 0.00253 \\
Cti & 0.01471 \\
Ctm & 0.50000 \\
Ccm & 0.00000 \\
AKC-T & 0.50000 \\
AKC-D & 0.00261 \\
AKC-U & 0.01709 \\
AKC-C & 0.00000 \\
\hline
\end{tabular}

Other Convergence Statistics

\begin{tabular}{lr}
\hline Digraph Density & \\
Standard deviation of indegree $\quad$ distribution & 1.075493 \\
Skewness of indegree $\quad$ distribution & 1.014203 \\
Standard deviation of outdegree distribution & 2.628892 \\
Skewness of outdegree $\quad$ distribution & 3.664220 \\
Corr. Coef. between in- and outdegree distributions & -0.366304 \\
Mean degree & 1.03448 \\
\hline
\end{tabular}


Table 4. Goodness of Fit Parameters Selection-Structure

\begin{tabular}{lrrrr} 
Structural Variable & Count & Mean & S.E. & GoF \\
\hline inAout-star(2.00) & 4.00 & 4.19 & 3.44 & -0.06 \\
2-in-star & 34.00 & 29.74 & 7.74 & 0.55 \\
2-out-star & 168.00 & 169.02 & 32.03 & -0.03 \\
3-in-star & 17.00 & 9.61 & 6.60 & 1.12 \\
3-out-star & 532.00 & 512.61 & 161.04 & 0.12 \\
A2P-D(2.00) & 168.00 & 165.37 & 30.78 & 0.09 \\
A2P-DU(2.00) & 101.00 & 96.10 & 16.21 & 0.30 \\
A2P-T(2.00) & 4.00 & 8.61 & 10.17 & -0.45 \\
A2P-TD(2.00) & 86.00 & 86.99 & 16.87 & -0.06 \\
A2P-TDU(2.00) & 68.67 & 66.94 & 11.84 & 0.15 \\
A2P-TU(2.00) & 19.00 & 17.72 & 6.52 & 0.20 \\
A2P-U(2.00) & 34.00 & 26.83 & 6.90 & 1.04 \\
Ain1out-star(2.00) & 3.50 & 6.84 & 7.61 & -0.44 \\
AinAout-star(2.00) & 3.50 & 3.22 & 2.43 & 0.12 \\
AinS(2.00) & 26.50 & 25.44 & 5.53 & 0.19 \\
AoutS(2.00) & 57.02 & 58.92 & 6.54 & -0.29 \\
arc & 58.00 & 58.04 & 3.70 & -0.01 \\
AT-D(2.00) & 0.00 & 1.02 & 1.49 & -0.69 \\
AT-DU(2.00) & 0.00 & 0.92 & 1.26 & -0.73 \\
AT-T(2.00) & 0.00 & 1.03 & 1.52 & -0.68 \\
AT-TD(2.00) & 0.00 & 1.03 & 1.50 & -0.68 \\
AT-TDU(2.00) & 0.00 & 0.96 & 1.34 & -0.71 \\
AT-TU(2.00) & 0.00 & 0.92 & 1.27 & -0.72 \\
AT-U(2.00) & 0.00 & 0.81 & 1.07 & -0.76 \\
Isolates & 0.00 & 1.15 & 1.03 & -1.11 \\
path2 & 4.00 & 8.64 & 10.22 & -0.45 \\
reciprocity & 0.00 & 0.02 & 0.13 & -0.14 \\
Sink & 34.00 & 34.07 & 2.12 & -0.03 \\
Source & 21.00 & 20.82 & 2.06 & 0.09 \\
T5 & 0.00 & 0.02 & 0.19 & -0.08 \\
T7 & 0.00 & 0.04 & 0.32 & -0.12 \\
T8 & 0.00 & 0.21 & 1.90 & -0.11 \\
T9(030T) & 0.00 & 1.04 & 1.53 & -0.68 \\
\hline
\end{tabular}

Note. For specification of structural variables, see Appendix B of Wang, Robbins and Pattison (2009). 
Exponential random graph models for management research 
Table 5. Goodness of Fit Parameters Selection-Attributes

\begin{tabular}{|c|c|c|c|c|}
\hline & Count & Mean & S.E & GoF \\
\hline Shareholder Value difference & 165.01 & 166.06 & 18.55 & -0.06 \\
\hline Shareholder Value reciprocity & 135.76 & 135.81 & 0.50 & -0.12 \\
\hline Shareholder Value in2star & 100.68 & 93.37 & 33.96 & 0.22 \\
\hline Shareholder Value out2star & 855.87 & 797.70 & 159.60 & 0.36 \\
\hline Shareholder Value path2 & 25.31 & 39.68 & 52.15 & -0.28 \\
\hline Shareholder Value product & 695.98 & 698.62 & 96.97 & -0.03 \\
\hline Shareholder Value reciprocity & 628.82 & 629.22 & 3.17 & -0.13 \\
\hline Shareholder Value Receiver & 156.32 & 155.55 & 20.27 & 0.05 \\
\hline Shareholder Value Sender & 238.79 & 250.12 & 20.76 & -0.06 \\
\hline Shareholder Value sum & 395.12 & 395.56 & 31.51 & -0.01 \\
\hline Shareholder Value sum reciprocity & 351.57 & 351.75 & 1.32 & -0.13 \\
\hline Change in Residual Income Rank difference & 157.20 & 157.50 & 21.80 & -0.01 \\
\hline Change in Residual Income Rank difference reciprocity & 123.51 & 123.55 & 0.55 & -0.07 \\
\hline Change in Residual Income Rank 2path & 11.55 & 27.55 & 59.00 & -0.27 \\
\hline Change in Residual Income Rank product & 595.06 & 562.31 & 82.91 & 0.38 \\
\hline Change in Residual Income Rank reciprocity & 581.85 & 582.10 & 3.56 & -0.07 \\
\hline Change in Residual Income Rank Receiver & 118.70 & 109.88 & 17.07 & 0.52 \\
\hline Change in Residual Income Rank Sender & 181.32 & 181.08 & 18.55 & 0.01 \\
\hline Change in Residual Income Rank sum & 300.01 & 290.96 & 26.32 & 0.35 \\
\hline Change in Residual Income Rank sum reciprocity & 262.08 & 262.18 & 1.08 & -0.09 \\
\hline Legal and Accounting activity reciprocity & 0.00 & 0.01 & 0.11 & -0.12 \\
\hline Legal and Accounting in2star & 0.00 & 0.19 & 0.77 & -0.25 \\
\hline Legal and Accounting interaction & 0.00 & 0.29 & 0.57 & -0.50 \\
\hline Legal and Accounting interaction reciprocity & 0.00 & 0.01 & 0.08 & -0.08 \\
\hline Legal and Accounting out2star & 163.00 & 161.55 & 32.15 & 0.05 \\
\hline Legal and Accounting 2path & 0.00 & 5.85 & 9.50 & -0.51 \\
\hline Legal and Accounting Receiver & 0.00 & 0.55 & 0.87 & -0.52 \\
\hline Legal and Accounting Sender & 32.00 & 32.05 & 3.09 & -0.02 \\
\hline Residual Income difference & 212.35 & 205.05 & 21.08 & 0.35 \\
\hline Residual Income difference reciprocity & 202.09 & 202.16 & 0.63 & -0.11 \\
\hline Residual Income in2star & 7.78 & 12.68 & 15.95 & -0.31 \\
\hline Residual Income out2star & 1001.33 & 922.58 & 193.55 & 0.51 \\
\hline Residual Income 2path & 13.17 & 30.85 & 59.59 & -0.30 \\
\hline Residual Income product & 75.53 & 82.01 & 53.52 & -0.12 \\
\hline Residual Income product reciprocity & 62.78 & 62.97 & 3.11 & -0.06 \\
\hline Residual Income Receiver & 18.02 & 21.68 & 13.36 & -0.27 \\
\hline Residual Income Sender & 195.93 & 196.57 & 20.82 & -0.03 \\
\hline
\end{tabular}


Exponential random graph models for management research

Residual Income sum

$213.95 \quad 218.16 \quad 22.29 \quad-0.19$

Residual Income reciprocity

$211.53 \quad 211.55 \quad 1.07 \quad-0.11$

Note. For interpretation of the selection effects on these variables, see the discussion in section

2. For a full specification, see Appendix B of Wang, Robbins and Pattison (2009). 
Figure 1. Examples of structural and dyadic selection variables
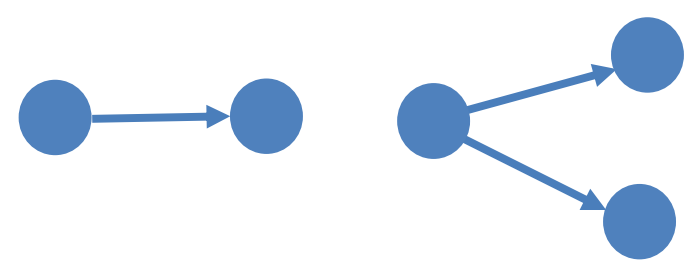

b) 2-outstar

(a) Arc
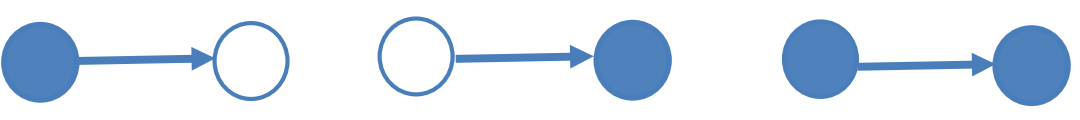

e) Attribute-based activity (sender effect)

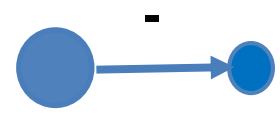

i) Difference f) Attribute-based popularity (receiver effect)

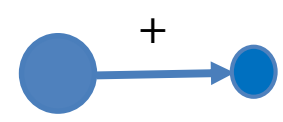

j) Sum

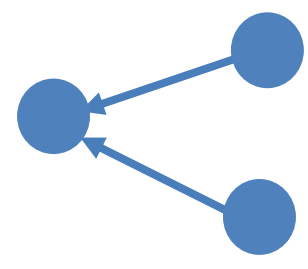

c) 2-instar

g) Attribute homophily

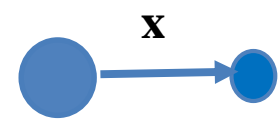

k) Product

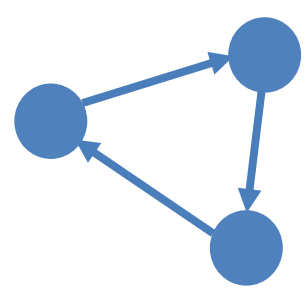

d) Cyclic triad

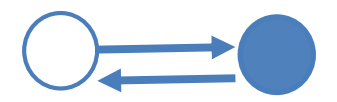

h) Attribute-based reciprocated activity

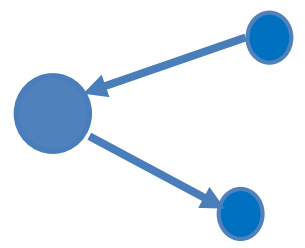

l) 2-path

Source: Adapted from Wang, Robins and Pattison (2009) 
Figure 2. All network components

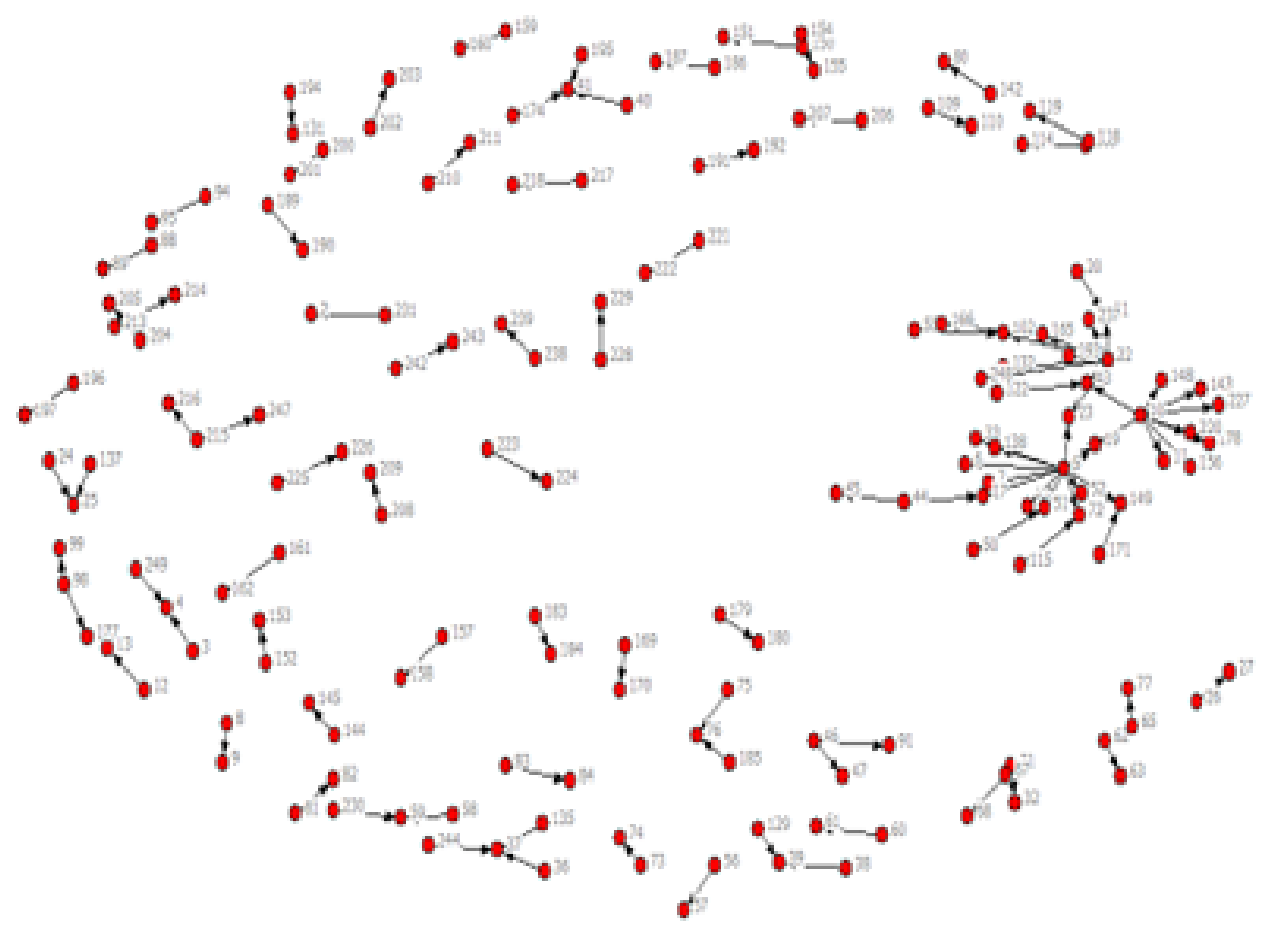


Figure 3. Main component

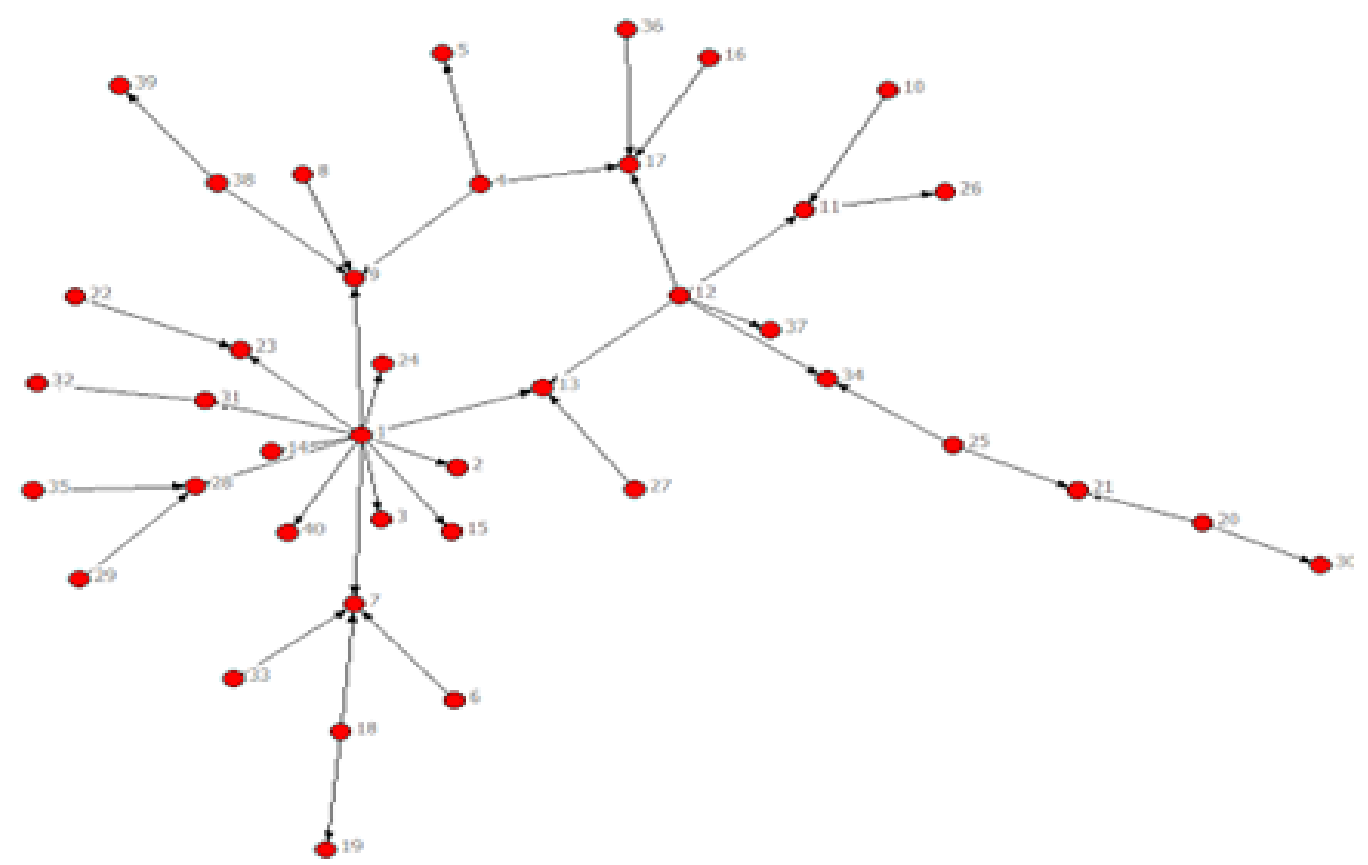

